\title{
ERRATUM
}

\section{Phosphorylation-enabled binding of SGO1-PP2A to cohesin protects sororin and centromeric cohesion during mitosis}

Hong Liu, Susannah Rankin and Hongtao Yu

Nat. Cell Biol. 15, 40-49 (2013); published online 16th December 2012; corrected online 20th December 2012

In the version of this Article initially published online and in print, the protein WAPL was mistakenly written as 'WAP1'. This has been corrected in the PDF and HTML versions of the Article.

\section{CORRIGENDUM}

\section{Humans put their eggs in more than one basket}

\section{Diana J. Laird}

Nat. Cell Biol. 15, 13-15 (2013)

In the print version of this News and Views article, there was an error in Fig. 1a. The blue line representing H3K27me3 should have risen between e11.5 and e12.5. The correct figure is shown below. This has been corrected in the PDF and HTML versions of the article.

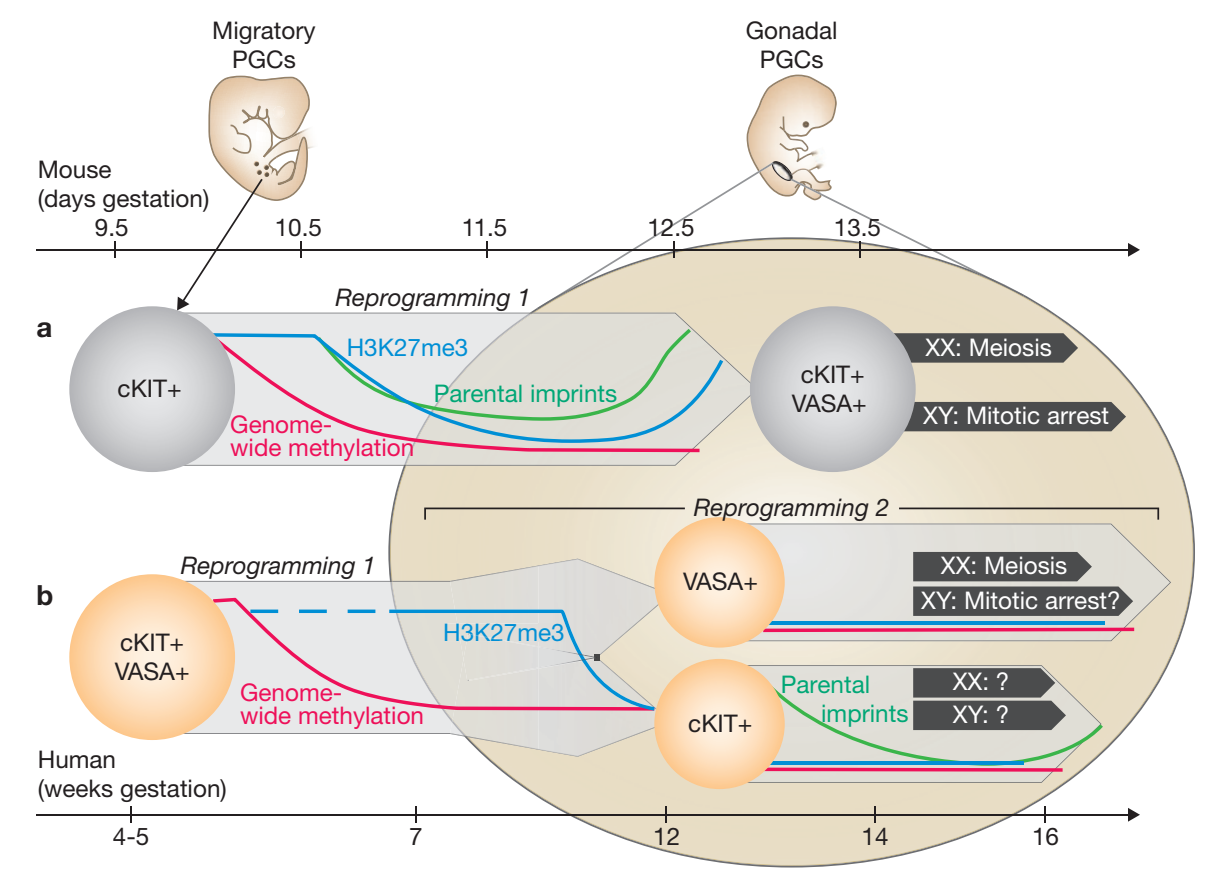

